\section{BMJ Open Respiratory Research}

\title{
Utility of radial endobronchial ultrasonography combined with transbronchial lung cryobiopsy in patients with diffuse parenchymal lung diseases: a multicentre prospective study
}

\author{
Minoru Inomata (D) , ${ }^{1}$ Naoyuki Kuse, ${ }^{1}$ Nobuyasu Awano, ${ }^{1}$ Mari Tone, ${ }^{1}$ \\ Hanako Yoshimura, ${ }^{1}$ Tatsunori Jo, ${ }^{1}$ Jonsu Minami, ${ }^{1}$ Kohei Takada, ${ }^{1}$ Yutaka Muto, ${ }^{1}$ \\ Kazushi Fujimoto, ${ }^{1}$ Akinori Harada, ${ }^{2}$ Yuan Bae, ${ }^{3}$ Toshio Kumasaka, ${ }^{3}$ \\ Hideaki Yamakawa, ${ }^{4}$ Shintaro Sato, ${ }^{4}$ Kazunori Tobino, ${ }^{5}$ Hidekazu Matsushima, ${ }^{4}$ \\ Tamiko Takemura, ${ }^{3,6}$ Takehiro Izumo ${ }^{1}$
}

\begin{abstract}
To cite: Inomata M, Kuse N, Awano N, et al. Utility of radial endobronchial ultrasonography combined with transbronchial lung cryobiopsy in patients with diffuse parenchymal lung diseases: a multicentre prospective study. BMJ Open Resp Res 2021;8:e000826. doi:10.1136/ bmjresp-2020-000826
\end{abstract}

Received 5 November 2020 Revised 14 December 2020 Accepted 17 December 2020

Check for updates

C) Author(s) (or their employer(s)) 2021. Re-use permitted under CC BY-NC. No commercial re-use. See rights and permissions. Published by BMJ.

For numbered affiliations see end of article.

Correspondence to Dr Minoru Inomata; inomataminoru@nms.ac.jp

\section{ABSTRACT}

Background Radial endobronchial ultrasonography (REBUS) has been used in conjunction with transbronchial lung cryobiopsy (TBLC) to diagnose diffuse parenchymal lung disease (DPLD) and to decrease the risk of bleeding complications. The diagnostic utility of different R-EBUS signs, however, remains unknown.

Objectives This study aimed to determine whether different R-EBUS signs could be used to more accurately diagnose DPLD and whether bronchial bleeding could be prevented with use of R-EBUS during TBLC.

Method Eighty-seven patients with DPLD were included in this multicentre prospective study, with 49 patients undergoing R-EBUS. R-EBUS signals were characterised as displaying either dense or blizzard signs. Pathological confidence of specimens obtained from TBLC was compared between patients with dense versus blizzard signs, and severity of bronchial bleeding was determined based on whether R-EBUS was performed or not.

Results All patients with dense signs on R-EBUS showed consolidation on high-resolution CT (HRCT) imaging. Pathological confidence of lung specimens was significantly higher in patients with dense signs versus those with blizzard signs $(p<0.01)$ and versus those who did not undergo R-EBUS $(p<0.05)$. Patients who underwent TBLC with R-EBUS were more likely to experience no or mild bronchial bleeding than patients who did not undergo R-EBUS $(p<0.01)$, with shorter procedure times $(p<0.01)$. Conclusions The dense R-EBUS sign corresponded with consolidation on HRCT. High-quality lung specimens may be obtainable when the dense sign is observed on R-EBUS, and R-EBUS combined with TBLC may reduce risk of bronchial bleeding and shorten procedure times.

\section{INTRODUCTION}

Transbronchial lung cryobiopsy (TBLC) is increasingly being used to diagnose diffuse parenchymal lung diseases (DPLD) and to

\section{Key messages}

This multicentre prospective study investigated the utility and safety of radial endobronchial ultrasonography (R-EBUS) combined with transbronchial lung cryobiopsy (TBLC) for improvement of diagnostic yield and for controlling bronchial bleeding in patients with diffuse parenchymal lung disease.

Pathological confidence of lung specimens was significantly higher in patients with dense signs versus those with blizzard signs and versus those who did not undergo R-EBUS, with more minor bronchial bleeding in patients who underwent R-EBUS than in those who did not undergo R-EBUS.

- The reader will find that the dense sign may increase the confidence level in pathological diagnoses of TBLC samples in patients showing consolidation on high-resolution CT and that R-EBUS may decrease the risk of bronchial bleeding.

improve diagnostic confidence during multidisciplinary diagnoses. ${ }^{1-3}$ TBLC and surgical lung biopsy (SLB)-based multidisciplinary discussion (MDD) diagnoses have been reported to have excellent concordance, with a $70.8 \%$ histopathological agreement. ${ }^{4}$ On the other hand, MDD diagnoses from TBLC and SLB have also been reported to have poor concordance, with a $38 \%$ agreement in patients with interstitial lung disease (ILD). ${ }^{5} \mathrm{SLB}$ is the gold standard for histological diagnosis in patients with suspected $\mathrm{ILD}^{6}$; however, in order to reduce mortality risk during SLB, high confidence in the TBLC-based pathological diagnosis is required.

The incidence of reported complications related to TBLC varies widely, with bronchial bleeding being the most common potentially 
severe complication. Serious bronchial bleeding has been reported in up to $42 \%$ of patients undergoing TBLC, with rates of moderate bronchial bleeding reported to range from $1.8 \%$ to $47 \% .^{7-12}$ Management of bronchial bleeding is of paramount importance for lung sampling during TBLC, and improved diagnostic yields and prevention of bleeding are necessary for successful TBLC procedures.

Radial endobronchial ultrasonography (R-EBUS) has been widely used for diagnosis of solitary pulmonary lesions. In patients with ground-glass nodules, the so-called 'blizzard' and 'mixed blizzard' signs observed during R-EBUS have been reported to improve diagnostic yields during transbronchial lung biopsy. ${ }^{13}$ Recently, concomitant usage of R-EBUS during TBLC in patients with clinical and radiological features of DPLD has also been reported to increase utility, safety and diagnostic yield. ${ }^{14}$ Unfortunately, TBLC poses a high risk of bronchial bleeding, with $72.7 \%$ of patients with ILD experiencing this complication. ${ }^{15}$ Use of R-EBUS during TBLC, however, has been reported to reduce the frequency of bleeding complications in these patients. ${ }^{16}$

We have previously reported the safety and utility of TBLC with endobronchial balloon use, and our TBLC protocol was validated in a prospective multicentre study. ${ }^{17}$ The characteristics and diagnostic utility of specific R-EBUS signs obtained during TBLC for evaluation of patients with DPLD, however, remain unknown. Therefore, in this study, the utility of R-EBUS combined with TBLC was evaluated for improvement of diagnostic yield and for controlling bronchial bleeding in patients with DPLD.

\section{MATERIALS AND METHODS}

\section{Study design and participants}

This study was conducted at the Department of Respiratory Medicine at Japanese Red Cross Medical Center, Saitama Red Cross Hospital, and Iizuka Hospital from July 2018 through August 2019. Inclusion criteria were as follows: age $>20$ years, suspected or diagnosed DPLDs, and ability to give informed consent. Exclusion criteria were as follows: allergies to lidocaine, midazolam, flumazenil, or pethidine; high risk of bronchial bleeding; unsuitability for withholding of anticoagulation therapy for 1-7 days; or unstable severe comorbidities, including unstable angina, congestive heart failure, or severe bronchial asthma. Consecutive patients were enrolled if a pulmonologist determined that TBLC was needed for diagnostic purposes. The utility of R-EBUS was evaluated in 49 patients with DPLD and compared with 38 patients with DPLD who did not undergo R-EBUS.

\section{Bronchoscopy procedure}

A flexible bronchoscope (EB-580T or EB-580S (Fujifilm, Tokyo, Japan), or BF-1T290, BF1T-260, or BF-260 (Olympus, Tokyo, Japan)) was used for bronchoscopies. A flexible endotracheal tube (SACETT Suction Above Cuff Endotracheal Tube $8.0-8.5 \mathrm{~mm}$; Smiths Medical International, Minneapolis, Minnesota, USA) was used for airway control, and an endobronchial balloon (Fogarty catheter, E-080-4F; Edwards Life-Sciences, Irvine, California, USA) was used for bronchial blockade and haemostasis in all patients. R-EBUS was determined to be performed in conjunction with TBLC when high-resolution CT (HRCT) findings were indicative of DPLD and TBLC was performed for focal lesions in the bronchus, or when HRCT findings revealed several types of lesions, for example, ground-glass opacity (GGO) and consolidation in the same patient. A $1.4 \mathrm{~mm}, 20-\mathrm{MHz}$ radial probe (PB2020-M; Fujifilm, or UM-S20-17S; Olympus) was used for R-EBUS. An epinephrine-saline mixture (1:10000 epinephrine) was routinely administered at a dose of $2 \mathrm{~mL}$ just before and after TBLC.

\section{R-EBUS procedure and signs}

First, the bronchus for TBLC was selected in accordance with HRCT findings. The R-EBUS probe was inserted into the selected bronchus until the pleural surface was reached. The R-EBUS probe was then slowly withdrawn from the pleura to the hilum while confirming lesion locations using X-ray imaging, and the characteristics of R-EBUS signals were evaluated. This method helped clinicians to choose appropriate biopsy sites for TBLC and to identify blood vessels close to lesions. During R-EBUS, the blizzard sign, a whitish acoustic shadow of air-containing lung tissues, was identified according to previous reports. ${ }^{1318} 19$ The 'dense' sign was identified as a darker and more homogeneous signal with irregularly distributed mottling and occasional linear hyperechoic areas. TBLC sites were selected as those in which R-EBUS demonstrated blizzard or dense signs and an absence of blood vessels, with radiographic guidance. HRCT features associated with TBLC sites were also evaluated in patients with dense or blizzard signs.

\section{TBLC and endobronchial balloon}

Under intravenous deep anaesthesia with pethidine, midazolam, or fentanyl, as well as $2 \%$ lidocaine, the flexible bronchoscope was advanced to the bronchus chosen for TBLC. A $1.9 \mathrm{~mm}$ diameter flexible cryoprobe (ERBECRYO 2 system; Erbe Elektromedizin GmbH, Tubingen, Germany) was then introduced. The cryoprobe was withdrawn from the pleural surface at least $1-2 \mathrm{~cm}$ proximally, and the biopsy site was determined with or without R-EBUS signals, with radiographic guidance (figure 1). The cryoprobe was cooled for 6 to $7 \mathrm{~s}$, and the cryoprobe with the attached lung specimen was removed en bloc with the bronchoscope. The endobronchial balloon was prophylactically inflated with $2-3 \mathrm{~mL}$ of air in all patients, and, after $60 \mathrm{~s}$ of inflation, the balloon was deflated. The specimen was placed in saline and inflated, by applying a negative pressure using a $20 \mathrm{~mL}$ syringe with saline for 60 to $120 \mathrm{~s}$, for histopathological evaluation. ${ }^{20} \mathrm{~A}$ major displacement of the inflated endobronchial balloon was defined as displacement without block bleeding, and a minor displacement was defined as displacement that maintained a haemostatic effect.

\section{Adverse events}

Adverse events were categorised as follows: (1) bronchial bleeding, (2) pneumothorax, (3) pneumonia, (4) respiratory 


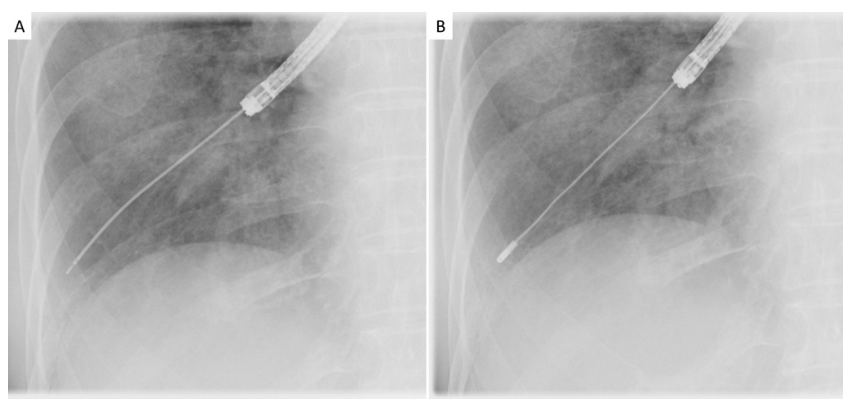

Figure 1 Radiographic guidance for selection of transbronchial lung cryobiopsy (TBLC) site. (A) The radial endobronchial ultrasonography (R-EBUS) probe was inserted into the bronchus selected for TBLC until the pleural surface was reached; thereafter, the R-EBUS probe was slowly withdrawn from the pleura to the hilum while confirming lesion locations using X-ray imaging and evaluating the characteristics of R-EBUS signals. (B) After the R-EBUS probe was withdrawn, the cryoprobe was inserted into the same bronchus and withdrawn from the pleural surface at least $1-2 \mathrm{~cm}$ proximally. The biopsy site was determined with or without R-EBUS signals, with radiographic guidance.

failure or (5) acute exacerbation of interstitial pneumonia. Adverse events were graded as serious, severe, moderate or mild. For all types of adverse events, 'serious' adverse events were defined as those that were life-threatening, and 'severe' adverse events were defined as those requiring surgical or radiological interventions or invasive mechanical ventilation. 'Moderate' or 'mild' adverse events were defined according to the severity of individual types of adverse events. 'Moderate' bronchial bleeding was defined as bleeding requiring administration of a cold saline or epinephrine-saline mixture three times or more; otherwise, it was defined as 'mild'. Bronchial bleeding due to TBLC was considered highly likely; therefore, a prophylactic epinephrine-saline mixture, which functioned as a local vasoconstrictor, was administered once, just before TBLC. The epinephrine-saline mixture was also routinely administered just after the TBLC. When bronchial bleeding occurred after TBLC, the epinephrine-saline mixture was administered a third time. If bronchial bleeding persisted, the mixture was administered as needed.

\section{Pathological evaluation and MDD diagnoses}

The pathological confidence level of tissue specimens was graded according to previous reports. ${ }^{21} 22$ Pathological confidence was classified as follows: level A (definite pathological diagnosis); level C (difficult to diagnose); or level B (between levels $\mathrm{A}$ and $\mathrm{C}$, and a probable diagnosis). The final diagnosis was achieved through MDD.

\section{Statistical analysis}

All data are presented as medians with ranges or absolute numbers with percentages. Differences between groups were compared using Student's t-test. $\chi^{2}$ or Fisher's exact tests were used for comparison of categorical variables. Data were analysed using JMP 10 V.10.0.2 (SAS Institute) and EZR

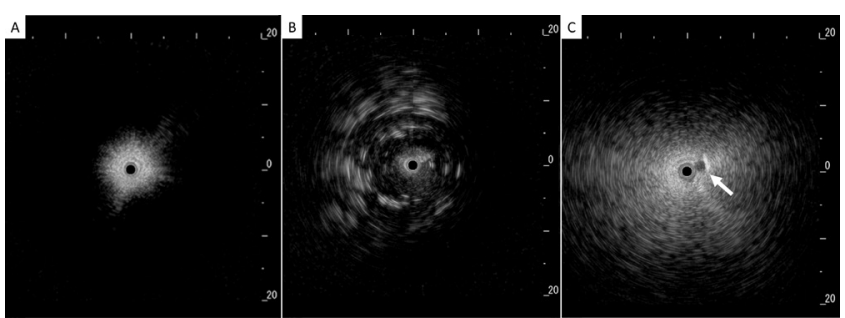

Figure 2 Representative signs on radial endobronchial ultrasonography. (A) Normal lung, (B) dense sign: dark and homogeneous signals with irregularly distributed mottling and linear hyperechoic areas, and (C) blizzard sign: noticeable increase in the intensity and radius of the whitish acoustic shadow with subsegmental pulmonary artery (white arrow).

(Saitama Medical Center, Jichi Medical University, Saitama, Japan). A two-tailed $p$ value of $<0.05$ was considered statistically significant.

\section{Patient and public involvement}

This research was performed without patient or public involvement.

\section{RESULTS}

\section{R-EBUS signs}

Data from 87 patients with DPLD were analysed in this study. In the 49 patients who underwent R-EBUS with TBLC, dense signs were observed in 18 patients, and blizzard signs were observed in 29 patients. Two patients displayed neither of these R-EBUS signals. Representative R-EBUS images are shown in figure 2, and representative ultrasonographic images demonstrating dense and blizzard signs, respectively, with corresponding HRCT and histopathological findings, are shown in figures 3 and 4 .
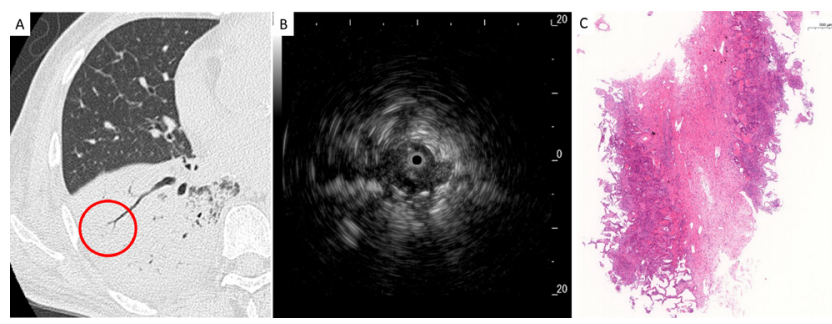

Figure 3 Representative radiological, ultrasonographic and pathological findings in patients with the dense sign. (A) Chest high-resolution CT showed a consolidation pattern in the right lower lobe, and radial endobronchial ultrasonography (R-EBUS) was evaluated in the encircled area, (B) R-EBUS showed a dense sign with dark and homogeneous signals, mottling and linear hyperechoic areas, and $(\mathrm{C})$ a lung specimen obtained by transbronchial lung cryobiopsy showed organisation in the alveoli and lymphocyte infiltration in the alveoli and alveolar wall with high pathological confidence (magnification,×2.6). 


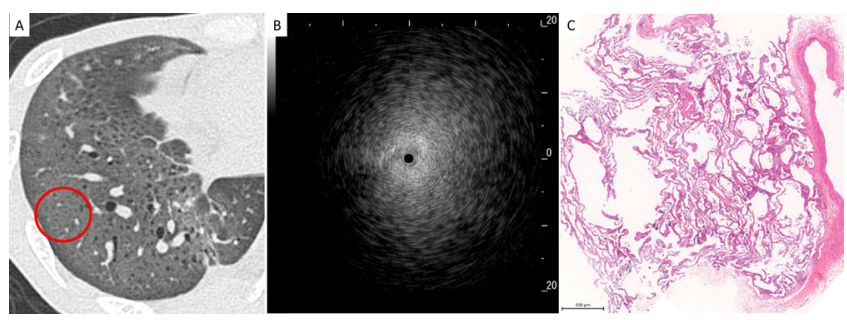

Figure 4 Representative radiological, ultrasonographic and pathological findings in patients with the blizzard sign. (A) Chest high-resolution CT showed ground-glass opacity in the right lower lobe, and radial endobronchial ultrasonography (R-EBUS) was evaluated in the encircled area, (B) R-EBUS showed a blizzard sign with a whitish acoustic shadow of air-containing lung tissue, and (C) a lung specimen obtained by transbronchial lung cryobiopsy showed diffuse cellular and fibrous alveolitis (magnification, $\times 3$ ).

\section{Patient characteristics}

Patient characteristics are shown in table 1. All patients with dense signs demonstrated consolidation at TBLC sites on HRCT imaging. There were significant differences in lobar locations of TBLCs $(\mathrm{p}<0.01)$.

\section{Pathological evaluation and diagnosis of MDD}

There were no significant differences in the median areas of TBLC specimens between patients who had dense or

Table 1 Characteristics of patients with dense versus blizzard signs on radial endobronchial ultrasonography

\begin{tabular}{|c|c|c|c|}
\hline & $\begin{array}{l}\text { Dense sign } \\
(n=18)\end{array}$ & $\begin{array}{l}\text { Blizzard } \\
\text { sign } \\
(n=29)\end{array}$ & $P$ value \\
\hline Age (years) & 70 (27-80) & 70 (33-81) & 0.16 \\
\hline Gender (female/male) & $7 / 11$ & $12 / 17$ & 0.86 \\
\hline $\begin{array}{l}\text { HRCT features at } \\
\text { TBLC site }\end{array}$ & & & - \\
\hline Consolidation & $18(100)$ & 0 & \\
\hline Reticulation & 0 & $15(51.7)$ & \\
\hline $\begin{array}{l}\text { Ground-glass } \\
\text { opacity }\end{array}$ & 0 & $13(44.8)$ & \\
\hline Nodules & 0 & $1(3.4)$ & \\
\hline $\begin{array}{l}\text { Cryobiopsies per } \\
\text { patient }\end{array}$ & $3(1-4)$ & $3(1-4)$ & 0.08 \\
\hline $\begin{array}{l}\text { Lobar location of } \\
\text { TBLC }\end{array}$ & & & $<0.01$ \\
\hline Right upper lobe & $2(4.8)$ & $11(13.6)$ & \\
\hline Right middle lobe & $4(9.5)$ & $1(1.2)$ & \\
\hline Right lower lobe & $14(33.3)$ & $50(61.7)$ & \\
\hline Left upper lobe & 7 (16.7) & 0 & \\
\hline Left lower lobe & $15(35.7)$ & $19(23.5)$ & \\
\hline
\end{tabular}

Data are presented as medians (ranges) or numbers (percentages). HRCT, high-resolution CT; TBLC, transbronchial lung cryobiopsy. blizzard signs; however, pathological confidence levels were significantly higher in patients who had dense signs than in patients who had blizzard signs $(\mathrm{p}<0.01)$ (analysis 1 in table 2). Similarly, there were no significant differences in median areas of TBLC specimens between patients with dense signs undergoing R-EBUS and patients who did not undergo R-EBUS; however, pathological confidence levels of specimens were significantly higher in patients who had dense signs than in patients who did not undergo R-EBUS $(\mathrm{p}<0.05)$ (analysis 2 in table 2). R-EBUS combined with TBLC for specimens with pathological confidence levels of $\mathrm{A}$ and $\mathrm{B}$ had a diagnostic yield of $83.4 \%$ in patients with a dense sign and $79.3 \%$ in patients with a blizzard sign. Table 3 shows the MDD diagnoses obtained after review of clinical, radiological and pathological features.

\section{Adverse events}

No or only mild bronchial bleeding occurred significantly more frequently in patients who underwent TBLCs with R-EBUS than in patients who did not undergo R-EBUS $(\mathrm{p}<0.01$; table 4$)$. No severe or serious adverse events, including bronchial bleeding, pneumothorax, pneumonia, acute exacerbations of ILD, or respiratory failure, were reported in any study patients.

\section{Bronchoscopic intervention}

The procedure time was significantly shorter in patients who underwent TBLC with R-EBUS than in patients who did not undergo R-EBUS ( $\mathrm{p}<0.01$; table 5$)$. There were no significant differences in the frequencies of displacements or ruptures of endobronchial balloons in patients who did or did not undergo R-EBUS.

\section{DISCUSSION}

This study demonstrated the utility of R-EBUS combined with TBLC for diagnosis of DPLD and for reduction of bronchial bleeding. It suggested that identification of the dense sign on R-EBUS can help clinicians to obtain high-quality lung specimens. In addition, concomitant usage of R-EBUS during TBLC may reduce the risk of bronchial bleeding by avoidance of lung tissue sampling near major vessels.

Previous studies have suggested that R-EBUS during TBLC may increase the diagnostic yield and reduce the risk of adverse events because this procedure may help clinicians to choose the most appropriate areas for lung sampling. ${ }^{14162324}$ The diagnostic yield of R-EBUS combined with TBLC for the diagnosis of DPLD has been reported to range from $79 \%$ to $92.5 \%{ }^{1423}$; however, there have been few reports related to the diagnostic utility of the R-EBUS procedure combined with TBLC for DPLD. An R-EBUS signal corresponding to a 'solid' sign has been reported in patients with lung cancer, ${ }^{25}$ and the diagnostic yield of R-EBUS-guided transbronchial biopsy was higher in patients with solid malignancies than in those with non-solid malignancies. ${ }^{26}$ To our knowledge, this study was the first to describe a similar 'dense' sign on R-EBUS in patients with DPLD, which we believe may result 
Table 2 Comparison of pathological evaluations of transbronchial lung cryobiopsies in patients with dense versus blizzard signs on radial endobronchial ultrasonography (R-EBUS) and versus patients who did not undergo R-EBUS

\begin{tabular}{|c|c|c|c|c|c|}
\hline & & Analysis 1 & & Analysis 2 & \\
\hline & $\begin{array}{l}\text { Dense sign } \\
(n=18)\end{array}$ & $\begin{array}{l}\text { Blizzard sign } \\
(n=29)\end{array}$ & $P$ value & $\begin{array}{l}\text { Without R-EBUS } \\
(n=38)\end{array}$ & $P$ value \\
\hline Median area $\left(\mathrm{mm}^{2}\right)$ & $12(4-40)$ & $15(1-48)$ & 0.73 & $18(2-60)$ & 0.13 \\
\hline Pathological confidence & & & $<0.01$ & & $<0.05$ \\
\hline Level A & $10(55.6)$ & $4(13.8)$ & & 13 (34.2) & \\
\hline Level B & $5(27.8)$ & $19(65.5)$ & & $23(60.5)$ & \\
\hline Level C & $3(16.7)$ & $6(20.7)$ & & $2(5.3)$ & \\
\hline
\end{tabular}

Data are presented as medians (ranges) or numbers (percentages).

in an increased diagnostic yield of TBLC when combined with R-EBUS compared with TBLC without R-EBUS.

In patients with lung cancer, GGO lesions evaluated with R-EBUS have been shown to demonstrate blizzard or

Table 3 Multidisciplinary discussion diagnoses in patients with dense and blizzard signs who underwent radial endobronchial ultrasonography (R-EBUS) and in patients who did not undergo R-EBUS

\begin{tabular}{|c|c|c|c|}
\hline & \multicolumn{2}{|c|}{ With R-EBUS } & \multirow[b]{2}{*}{$\begin{array}{l}\text { Without } \\
\text { R-EBUS } \\
(n=38)\end{array}$} \\
\hline & $\begin{array}{l}\text { Dense sign } \\
(n=18)\end{array}$ & $\begin{array}{l}\text { Blizzard } \\
\text { sign } \\
(n=29)\end{array}$ & \\
\hline Idiopathic pulmonary fibrosis & 0 & $6(20.7)$ & $7(18.4)$ \\
\hline $\begin{array}{l}\text { Idiopathic nonspecific } \\
\text { interstitial pneumonia }\end{array}$ & 0 & 0 & $6(15.8)$ \\
\hline $\begin{array}{l}\text { Cryptogenic organising } \\
\text { pneumonia }\end{array}$ & $2(11.1)$ & $3(10.3)$ & $1(2.6)$ \\
\hline $\begin{array}{l}\text { Acute fibrinous and } \\
\text { organising pneumonia }\end{array}$ & $1(5.6)$ & 0 & 0 \\
\hline $\begin{array}{l}\text { Unclassified interstitial } \\
\text { pneumonia }\end{array}$ & 0 & $4(13.8)$ & $8(21.1)$ \\
\hline $\begin{array}{l}\text { Chronic hypersensitivity } \\
\text { pneumonitis }\end{array}$ & 0 & $3(10.3)$ & $6(15.8)$ \\
\hline $\begin{array}{l}\text { Connective tissue disease- } \\
\text { associated interstitial lung } \\
\text { disease }\end{array}$ & $6(33.3)$ & $2(6.9)$ & $7(18.4)$ \\
\hline $\begin{array}{l}\text { Smoking-related interstitial } \\
\text { lung disease }\end{array}$ & 0 & $1(3.4)$ & 0 \\
\hline $\begin{array}{l}\text { Chronic eosinophilic } \\
\text { pneumonia }\end{array}$ & $2(11.1)$ & $2(6.9)$ & 0 \\
\hline Sarcoidosis & $1(5.6)$ & 0 & $1(2.6)$ \\
\hline Pulmonary amyloidosis & 0 & 0 & $1(2.6)$ \\
\hline $\begin{array}{l}\text { Eosinophilic granulomatosis } \\
\text { with polyangiitis }\end{array}$ & $1(5.6)$ & 0 & 0 \\
\hline $\begin{array}{l}\text { Drug-induced interstitial lung } \\
\text { disease }\end{array}$ & $1(5.6)$ & $3(10.3)$ & 0 \\
\hline Radiation pneumonitis & 0 & $1(3.4)$ & 0 \\
\hline Diffuse alveolar haemorrhage & 0 & $1(3.4)$ & 0 \\
\hline $\begin{array}{l}\text { Multicentric Castleman } \\
\text { disease }\end{array}$ & $1(5.6)$ & 0 & $1(2.6)$ \\
\hline Viral pneumonia & 0 & $1(3.4)$ & 0 \\
\hline Others* & $3(16.7)$ & $2(6.9)$ & 0 \\
\hline
\end{tabular}

Data are presented as numbers (percentages).

*Suspected granulomatous disease, and drug-induced lung disease without obvious histological findings. mixed blizzard signs, and R-EBUS has been shown to play an important role in locating GGOs prior to lung biopsies. ${ }^{13}$ In contrast, solid lesions observed on CT imaging appear darker and more homogeneous on R-EBUS in patients with solitary pulmonary nodules. ${ }^{27}$ Recently, blizzard and mixed blizzard signs have been evaluated in patients with clinical and radiological findings suggestive of DPLD ${ }^{14}$; however, to the best of our knowledge, there have been no previous reports of dense R-EBUS signals in DPLD patients who display a consolidation pattern on HRCT. In this study, the dense sign was only observed in patients who displayed consolidation on HRCT, with a consolidation pattern being more common among patients with a dense sign than a blizzard sign. Therefore, a dense sign was a characteristic R-EBUS pattern in patients with consolidation on HRCT.

The diagnostic yield of R-EBUS during bronchoscopy in patients with solid peripheral pulmonary malignancies has been shown to be higher than in patients with non-solid malignancies ${ }^{26}$; however, R-EBUS signals in DPLD patients with a consolidation pattern on HRCT have not previously been reported. The pathological confidence of lung specimens from patients with associated dense signs was higher than in patients with blizzard signs and in those who did not undergo R-EBUS; therefore, the dense sign on R-EBUS may increase the diagnostic yield.

A dense sign was only observed in patients showing consolidation on HRCT. When the R-EBUS probe was positioned in the middle of a lesion in the proper bronchus, a dense sign was revealed; however, when the R-EBUS probe was positioned around the lesion or inserted into the wrong bronchus, some patients also demonstrated a blizzard sign, even when showing consolidation on HRCT. The density of

Table 4 Bronchial bleeding in patients who did or did not undergo radial endobronchial ultrasonography (R-EBUS) in conjunction with transbronchial lung cryobiopsy

\begin{tabular}{lcll}
\hline & $\begin{array}{l}\text { With R- } \\
\text { EBUS } \\
(\mathbf{n}=49)\end{array}$ & $\begin{array}{l}\text { Without R- } \\
\text { EBUS } \\
(\mathbf{n}=38)\end{array}$ & P value \\
\hline $\begin{array}{l}\text { Bronchial bleeding } \\
\text { None/mild }\end{array}$ & $45(91.8)$ & $25(65.8)$ & $<0.01$ \\
Moderate & $4(8.2)$ & $13(34.2)$ & \\
\hline
\end{tabular}

Data are presented as numbers (percentages). 
Table 5 Characteristics of bronchoscopic interventions in patients who did or did not undergo radial endobronchial ultrasonography (R-EBUS) in conjunction with transbronchial lung cryobiopsy

\begin{tabular}{|c|c|c|c|}
\hline & $\begin{array}{l}\text { With R- } \\
\text { EBUS } \\
(n=49)\end{array}$ & $\begin{array}{l}\text { Without R- } \\
\text { EBUS } \\
(n=38)\end{array}$ & $P$ value \\
\hline Procedure time (min) & $31(18-49)$ & $37(18-71)$ & $<0.01$ \\
\hline $\begin{array}{l}\text { Cryobiopsies per } \\
\text { patient }\end{array}$ & $3(1-4)$ & $3(1-5)$ & 0.22 \\
\hline $\begin{array}{l}\text { Displacement of } \\
\text { endobronchial } \\
\text { balloon }\end{array}$ & $(n=116)$ & $(n=87)$ & \\
\hline $\begin{array}{l}\text { Major } \\
\text { displacement }\end{array}$ & & & 0.51 \\
\hline Upper lobe & $1(0.9)$ & 0 & \\
\hline Middle lobe & 0 & 0 & \\
\hline Lower lobe & $2(1.7)$ & 0 & \\
\hline $\begin{array}{l}\text { Minor } \\
\text { displacement }\end{array}$ & & & 0.11 \\
\hline Upper lobe & $1(0.9)$ & $1(1.1)$ & \\
\hline Middle lobe & $1(0.9)$ & 0 & \\
\hline Lower lobe & $8(6.9)$ & $1(1.1)$ & \\
\hline Rupture & $3(2.6)$ & 0 & 0.26 \\
\hline
\end{tabular}

Data are presented as medians (ranges) or numbers (percentages).

the internal structure of lesions may account for these differences in R-EBUS signals. This study suggests that identifying R-EBUS signals is important for obtaining high-quality lung specimens and that TBLC sites should be chosen to correspond with dense R-EBUS signs in patients with suspected DPLD and consolidation on HRCT. Therefore, the presence of the dense sign should be ascertained at TBLC sites in patients showing consolidation on HRCT.

Usual interstitial pneumonia (UIP), which is characterised by geographical heterogeneity in subpleural and/or paraseptal distributions of fibrosis, generally requires SLB for diagnosis. According to 2018 idiopathic pulmonary fibrosis (IPF) guidelines, TBLC is not recommended for the diagnosis of UIP/IPF. ${ }^{28}$ Therefore, in the present study, the higher pathological confidence of specimens in patients with dense signs than in patients with blizzard signs or in those who did not undergo R-EBUS may be due to a lack of patients with IPF in the dense sign group. However, the UIP pattern has been reported to be identifiable with high pathological confidence in patients undergoing TBLC, ${ }^{29}$ and the diagnostic yield of the UIP pattern has been reported to be up to $66 \%$ during TBLC. ${ }^{730}$ In addition, interobserver variability between pathologists was similar for the diagnosis of the UIP pattern using either TBLC or SLB. ${ }^{3}$ Therefore, we believe that the type of underlying disease had little influence on the pathological confidence of specimens in this study. Nevertheless, TBLC has been reported to increase the diagnostic confidence in the MDD of $\mathrm{IPF}^{3}$ and further study is needed to identify the diagnostic yield of the UIP pattern using TBLC.

In a prospective observational study of 114 patients suspected of having ILD, there were a small number of patients who experienced minor or moderate bronchial bleeding during R-EBUS combined with TBLC. ${ }^{23}$ Another retrospective study demonstrated that it may be possible to prevent bronchial bleeding by using R-EBUS during TBLC. ${ }^{16}$ In the present study, R-EBUS facilitated identification of major vessels close to lesions and establishment of an exact target location for TBLCs.

Use of an endobronchial balloon in all patients was another key method for maintaining haemostasis in this study, with no significant differences in the rates of displacements or ruptures of endobronchial balloons, numbers of cryobiopsies, or locations of TBLCs in patients who did or did not undergo R-EBUS. Therefore, the statistically significantly shorter procedure times in patients who underwent R-EBUS may be secondary to the statistically significantly less frequent occurrence of moderate bronchial bleeding in this group. Prevention of bronchial bleeding and shortening of procedure times may be other advantages to the use of R-EBUS with TBLC.

There were several limitations to the present study. First, selection bias may have been present because different pulmonologists at each institution determined the necessity for R-EBUS; accordingly, a randomised trial is needed for a more thorough investigation of this question. Second, none of the patients in this study underwent SLB; therefore, comparisons of R-EBUS combined with TBLC and SLB were not possible.

\section{CONCLUSION}

This multicentre prospective study demonstrated the utility of R-EBUS combined with TBLC for the diagnosis of DPLD. Lung specimens with high pathological confidence may be obtained during TBLC when patients show the dense sign on R-EBUS. The R-EBUS procedure may also minimise the risk of bronchial bleeding during TBLC, by avoidance of major vessels, and may shorten the procedure time.

\section{Author affiliations}

${ }^{1}$ Department of Respiratory Medicine, Japanese Red Cross Medical Center, Tokyo, Japan

2Department of Radiology, Japanese Red Cross Medical Center, Tokyo, Japan ${ }^{3}$ Department of Pathology, Japanese Red Cross Medical Center, Tokyo, Japan ${ }^{4}$ Department of Respiratory Medicine, Saitama Red Cross Hospital, Saitama, Japan

${ }^{5}$ Department of Respiratory Medicine, lizuka Hospital, Fukuoka, Japan ${ }^{6}$ Department of Pathology, Kanagawa Cardiovascular and Respiratory Center, Kanagawa, Japan

Correction notice This article has been corrected since it first published. The provenance and peer review statement has been included.

Acknowledgements The authors wish to acknowledge Ai Ushiwata from the Department of Clinical Medicine (Biostatistics) and the School of Pharmacy at Kitasato University for her help with statistical analysis for this study.

Contributors All authors provided final approval of the manuscript version to be published and agreed to be accountable for all aspects of the work in ensuring that questions related to the accuracy or integrity of any part of the 
work are appropriately investigated and resolved. Ml: contributed to the design and implementation of the research, analysis of the results, and drafting of the manuscript. NK, NA, MT, HY, TJ, JM, KT, YM, KF, HY, SS, KT, and HM: contributed to acquisition and analysis of data and provided critical revision of the article. $\mathrm{AH}$ : performed radiological analysis and provided critical revision of the article. YB and TK: performed pathological analysis and provided critical revision of the article. TT: contributed to pathological analysis and interpretation and provided critical revision of the article. Tl: contributed to the design and implementation of the research, analysis of the results and critical revision of the article.

Funding The authors have not declared a specific grant for this research from any funding agency in the public, commercial or not-for-profit sectors.

Competing interests None declared.

Patient and public involvement Patients and/or the public were not involved in the design, or conduct, or reporting, or dissemination plans of this research.

Patient consent for publication Not required.

Ethics approval This study was approved by the Institutional Review Board of the Japanese Red Cross Medical Center (No. 901) and confirmed by the ethics committees of each individual site. The study procedures were performed from July 2018 through August 2019. This study was registered on the University Hospital Medical Information Network (UMIN 000033284). Written informed consent was obtained from all patients prior to enrolment in the study.

Provenance and peer review Not commissioned; externally peer reviewed.

Data availability statement Data are available upon reasonable request. The datasets generated and analysed during the current study are available from the corresponding author upon reasonable request.

Open access This is an open access article distributed in accordance with the Creative Commons Attribution Non Commercial (CC BY-NC 4.0) license, which permits others to distribute, remix, adapt, build upon this work non-commercially, and license their derivative works on different terms, provided the original work is properly cited, appropriate credit is given, any changes made indicated, and the use is non-commercial. See: http://creativecommons.org/licenses/by-nc/4.0/.

ORCID iD

Minoru Inomata http://orcid.org/0000-0003-4149-9779

\section{REFERENCES}

1 Pajares V, Puzo C, Castillo D, et al. Diagnostic yield of transbronchial cryobiopsy in interstitial lung disease: a randomized trial.

Respirology 2014;19:900-6.

2 Ravaglia C, Wells AU, Tomassetti S, et al. Transbronchial lung cryobiopsy in diffuse parenchymal lung disease: comparison between biopsy from 1 segment and biopsy from 2 segments diagnostic yield and complications. Respiration 2017;93:285-92.

3 Tomassetti S, Wells AU, Costabel U, et al. Bronchoscopic lung cryobiopsy increases diagnostic confidence in the multidisciplinary diagnosis of idiopathic pulmonary fibrosis. Am J Respir Crit Care Med 2016;193:745-52.

4 Troy LK, Grainge C, Corte TJ, et al. Diagnostic accuracy of transbronchial lung cryobiopsy for interstitial lung disease diagnosis (COLDICE): a prospective, comparative study. Lancet Respir Med 2020;8:171-81.

5 Romagnoli M, Colby TV, Berthet J-P, et al. Poor concordance between sequential transbronchial lung Cryobiopsy and surgical lung biopsy in the diagnosis of diffuse interstitial lung diseases. Am J Respir Crit Care Med 2019;199:1249-56.

6 Miller JD, Urschel JD, Cox G, et al. A randomized, controlled trial comparing thoracoscopy and limited thoracotomy for lung biopsy in interstitial lung disease. Ann Thorac Surg 2000;70:1647-50.

7 Ravaglia C, Bonifazi M, Wells AU, et al. Safety and diagnostic yield of transbronchial lung cryobiopsy in diffuse parenchymal lung diseases: a comparative study versus video-assisted thoracoscopic lung biopsy and a systematic review of the literature. Respiration 2016:91:215-27.

8 Cascante JA, Cebollero P, Herrero S, et al. Transbronchial cryobiopsy in interstitial lung disease: are we on the right path? $J$ Bronchology Interv Pulmonol 2016;23:204-9.
9 Hagmeyer L, Theegarten D, Wohlschläger J, et al. The role of transbronchial cryobiopsy and surgical lung biopsy in the diagnostic algorithm of interstitial lung disease. Clin Respir J 2016;10:589-95.

10 Fruchter O, Fridel L, El Raouf BA, et al. Histological diagnosis of interstitial lung diseases by cryo-transbronchial biopsy. Respirology 2014;19:683-8.

11 Sriprasart T, Aragaki A, Baughman R, et al. A single US center experience of transbronchial lung cryobiopsy for diagnosing interstitial lung disease with a 2-scope technique. J Bronchology Interv Pulmonol 2017;24:131-5.

12 Ussavarungsi K, Kern RM, Roden AC, et al. Transbronchial cryobiopsy in diffuse parenchymal lung disease: retrospective analysis of 74 cases. Chest 2017;151:400-8.

13 Izumo T, Sasada S, Chavez C, et al. Radial endobronchial ultrasound images for ground-glass opacity pulmonary lesions. Eur Respir $J$ 2015;45:1661-8.

14 Abdelghani R, Thakore S, Kaphle U, et al. Radial endobronchial ultrasound-guided transbronchial Cryobiopsy. J Bronchology Interv Pulmonol 2019;26:245-9.

15 Hetzel J, Eberhardt R, Petermann C, et al. Bleeding risk of transbronchial cryobiopsy compared to transbronchial forceps biopsy in interstitial lung disease - a prospective, randomized, multicentre cross-over trial. Respir Res 2019;20:140.

16 Berim IG, Saeed Al, Awab A, et al. Radial probe ultrasound-guided Cryobiopsy. J Bronchology Interv Pulmonol 2017;24:170-3.

17 Inomata M, Kuse N, Awano N, et al. Prospective multicentre study on the safety and utility of transbronchial lung cryobiopsy with endobronchial balloon. ERJ Open Res 2020;6. doi:10.1183/23120541.00008-2020. [Epub ahead of print: 2206 2020].

18 Wang Memoli JS, Nietert PJ, Silvestri GA. Meta-Analysis of guided bronchoscopy for the evaluation of the pulmonary nodule. Chest 2012;142:385-93.

19 Herth FJF, Eberhardt R, Becker HD, et al. Endobronchial ultrasound-guided transbronchial lung biopsy in fluoroscopically invisible solitary pulmonary nodules: a prospective trial. Chest 2006:129:147-50.

20 Takemura T, Baba T, Niwa T. Histology for transbronchial lung cryobiopsy samples. In: Poletti V, ed. Transbronchial Cryobiopsy in diffuse parenchymal lung disease. Cham: Springer Cham, 2019: 67-73

21 Kuse N, Inomata M, Awano N, et al. Management and utility of transbronchial lung cryobiopsy in Japan. Respir Investig 2019:57:245-51.

22 Takashi N, Tamiko T, Erina T. Initial report of transbronchial lung cryobiopsy for diffuse parenchymal lung disease. Journal of the Japan Society for Respiratory Endoscopy 2018:40:453-8.

23 Gnass M, Filarecka A, Bartczak A, et al. Transbronchial lung cryobiopsy guided by radial mini-probe endobronchial ultrasound in interstitial lung diseases - a multicenter prospective study. Adv Respir Med 2020;88:123-8.

24 Gupta A, Youness H, Dhillon SS, et al. The value of using radial endobronchial ultrasound to guide transbronchial lung cryobiopsy. $J$ Thorac Dis 2019:11:329-34.

25 Kurimoto N, Murayama M, Yoshioka S, et al. Analysis of the internal structure of peripheral pulmonary lesions using endobronchial ultrasonography. Chest 2002;122:1887-94.

26 Huang C-T, Tsai Y-J, Ho C-C, et al. Radial endobronchial ultrasound-guided transbronchial biopsy for peripheral pulmonary malignancy: biopsy- or brushing-first? BMC Pulm Med 2019;19:193.

27 Eberhardt R, Ernst A, Herth FJF. Ultrasound-Guided transbronchial biopsy of solitary pulmonary nodules less than $20 \mathrm{~mm}$. Eur Respir $J$ 2009;34:1284-7.

28 Raghu G, Remy-Jardin M, Myers JL, et al. Diagnosis of idiopathic pulmonary fibrosis. An official ATS/ERS/JRS/ALAT clinical practice guideline. Am J Respir Crit Care Med 2018;198:e44-68.

29 Colby TV, Tomassetti S, Cavazza A, et al. Transbronchial cryobiopsy in diffuse lung disease: update for the pathologist. Arch Pathol Lab Med 2017:141:891-900.

30 Griff S, Schönfeld N, Ammenwerth W, et al. Diagnostic yield of transbronchial cryobiopsy in non-neoplastic lung disease: a retrospective case series. BMC Pulm Med 2014;14:171. 